\title{
DIE INDELING EN VERSPREIDING VAN DIL VOLKE VAN AFRIKA
}

By die behandeling van hierdie onderwerp kom die referent voor etlike moeilike metodologiese vraagstukke te staan. Uiteraard behels dit feitemateriaal wat geensins afdoende behandel kan word in die bestek van een voordrag nie. Daar is veral drie aspekte wat in aanmerking kom, t.w. die historiese, d.w.s. die tydstip of periode waarvan die beskrywing gegee moet word, die raskundige en die kulturele. Met die oog op die doel van ons eerste reeks voordragte, nl. om 'n algemene oriëntering te gee en ter aansluiting by die voorafgaande en die hieropvolgende referaat, sal 'n sekere seleksie met betrekking tot die belangrikste aspekte van die onderhawige tema gedoen moet word.

Vir sover dit die historiese betref, ontstaan die vraag: watter tydsbeeld wil ons gee van die mense van Afrika - prehistories, uit die Egiptiese tydperk, in die eerste eeue n.C., gedurende die $16 \mathrm{e}$ of teen die helfte van die 20 e eu? Want wie Afrika wil ken en begryp moet ook vanaf die begin besef dat hy hier met 'n veranderende situasie te doen het wat histories gegroei en gedurig van voorkoms gewissel het.

Eintlik is dit die taak van die historikus om die besonderhede uit te werk oor hierdie sy van die saak. Ek wil my dus nie skuldig mak aan oortreding op die vakgebied van ander nie, en dit boonop op die gevaar af om in allerlei vakwetenskaplike strikvalle te beland nie. Aan die ander kant is dit vir die volkekundige en vir die student van die Afrika-kulture dringend noodsaaklik om homself deeglike rekenskap te gee van die historiese verloop in Afrika tensy hy in die gees van die funksionalistiese skool van Malinowski en sy medestanders tevrede is met ' $n$ a-historiese analise van kultuurkomponente en hulle funksionering.

Hoewel ons kennis van die prehistorie van Afrika nog baie ver van volledig is, word hierdie kontinent argeologies van toenemende betekenis beskou. 'n Oorsig van die vrugte van argeologiese studie en navorsing in Afrika is dan ook van soveel betekenis en belangrikheid dat dit ' $n$ afsonderlike en meer gespesialiseerde voordrag regverdig.

Met inagneming van die hieropvolgende onderwerp skyn dit dus die aangewese weg te wees om 'n tydsbeeld van die Afrikanervolke te gee teen ongeveer die $16 \mathrm{e}$ tot die $18 \mathrm{e}$ eeu. Dit behels die periode van 
uitgebreide Europese aanraking met en belangstelling in Afrika as voorloper van die aktiewe kolonialisering oftewel die ,scramble for Africa" wat histories sou en moes uitloop op 'n verdeling van die kontinent in 'n aantal politiek-ekonomiese invloedsfere. Die keuse van hierdie periode het verder vir ons doel die voordeel dat dit min of meer 'n beeld gee van die situasie soos dit vandag nog ten opsigte van die volkeverspreiding vind. Weliswaar het die bevolkingskaart van Afrika gedurende hierdie eeue nie onveranderd gebly nie. Grootskaalse volksverskuiwinge, die opkoms en verval van inboorlingstate en -kulture het voorgekom, die slawehandel het beroering en onrus ten gevolge gehad, maar aan die breë lyne van die rassegrens het dit geen wesentlike verandering gemaak nie.

Tot vandag toe beskik ons nog oor geen volledige, uitvoerige etnografiese beskrywing van Afrika nie. Daar is reeds baie verdienstelike werk gedoen, maar dan of in die vorm van afsonderlike, losstaande monografieë of in die vorm van afsonderlike, skematiese beskrywing. Die volledigste van sy soort is die Ethnographic Survey of Africa, wat onder inisiatief en beskerming van die International African Institute met prof. Daryll Forde as redakteur uitgevoer word en nog ver van afgehandel is. Vir ons doel meen ek dat 'n suiwer etnografiese behandeling van die onderwerp weens die tydsbeperking uiteraard te skematies en gevolglik vervelig sal wees. Dit kan nie veel meer wees as 'n inventaris van die name van volke en stamme met dié van hulle onderskeie woonplekke nie.

Om 'n tussenweg te probeer vind verkies ek dan om die aandag toe te spits op die groot rassegroepe. Maar instede van 'n suiwer raskundige, d.w.s. fisies-antropologiese verhandeling te lewer, dit dan te doen in enigsins etnologiese sin vir sover die rasgroepering ook 'n volkeen kultuurgroepering of ten minste die grondslag daarvoor vorm. In dié geval hoef dan ook nie soveel aandag gegee te word aan die verskillende beskouinge oor die herkoms en die geskiedenis van die rasse nie.

Vir sover dit die kultuur van hierdie groot indelinge betref, kan die aandag ook slegs op enkele punte toegespits word. Dit sal voldoende wees om in breë trekke die algemene kultuurpatroon op grondslag van die gewone onderskeiding tussen versamelaars, landbou- en herderskulture te skets, met enigsins meer klem op die ontwikkeling ten opsigte van die sosiaal-politieke organisasie en die staats- en volkswording. 
Seligman onderskei die volgende hoofgroepe ten opsigte van die volke van Afrika: die Khoisan (Hottentotte en Boesmans) en Negrito's, die Negers, die oostelike, noordelike en half-Hamiete (insluitende die Nilote) en die oostelike, suidelike en westelike Bantoe. Hierdie indelingsgrondslag word in hooftrekke ook gevolg deur die Tomlinsonkommissie in sy kaart oor die volksgroepe in Afrika. Hoewel die bekende werk van James George Frazer die titel dra van The Native Races of Africa and Madagascar, bevat dit in werklikheid geen stelselmatige beskrywing van die rasgroepe en hulle verdeling nie, maar slegs uittreksels uit bronne oor dié volke en stamme. Walter Hirschberg in Bernatzik se Neue Grosze Völkerkunde I volg in sy beskrywing van die volkskulture van Afrika die ekonomiese kultuurgrondslag eerder as die rasse-identiteit as uitgangspunt. Nogtans bevat dit heelwat verwysings na die rasseverwantskap, en in sy verskillende kaarte word 'n aanduiding gevind van die rasseverspreiding. Hy is egter minder geneig tot die breë vereenvoudigde indeling van Seligman en gee in selfs groter besonderhede as die Tomlinsonverslag volkeregroeperings eerder as rasse-indelings.

Die enigste ernstige problematiek en moontlike geskilpunte betref dus eintlik die vraag waar sekere volke of stamme raskundig sou kan inpas. Grondoorsaak hiervan is dat die kultuur- en rassegrense as gevolg van eeuelange aanrakings - hetsy vreedsaam of gewelddadig en volksverskuiwinge nie parallel loop nie en allerlei bloed- en kultuurvermenging plaasgevind het. Ons indeling van die volke van Afrika is basies dus ook geen suiwer rassiese indeling nie maar berus eweseer op kulturele gronde en veral op taalooreenkomste of -onderskeidinge. Selfs ons begrip Bantoe staan volkekundig eintlik nie op pote nie, tensy ons daaronder verstaan Bantoe-sprekende volke.

Dit word feitlik algemeen aanvaar dat die sg. Khoisan, d.w.s. die Boesmans en die Hottentotte, die woongebied waarin die blankes hulle teen die $16 \mathrm{e}$ en 17e eeue aangetref het, vanuit die noorde, m.a.w. Oosen Sentraal-Oos-Afrika, binnegekom het. Hoewel die enigste Boesmans - in baie opsigte ook al sterk verbaster in rassiese en kulturele sin vandag slegs nog gevind word in die noordelike dele van S.W.A. en van die Kalahari met 'n klein groepie in die Lake Chrissie-gebied, was hierdie interessante en waarskynlik primitiefste en oudste bekende inwoners van suidelike Afrika blykbaar versprei oor die hele gebied min of meer suid van die Sambesie. Getuie hiervan is sowel hulle kenmerkende rotstekeninge en -gravures (op grond waarvan Stow twee Boesman- 
groepe, t.w. die grot- en koppiebewoners onderskei) as oorblyfsels van klip- en ander werktuie, sekere plekname en slselette.

Die enigste ander dwergvolk van $\Lambda$ frika is die Pigmeë van die Kongo. Sommige is geneë om op grond van hierdie ooreenkoms die dwergagtigheid -. 'n verwantskap tussen die Boesmans en die Pigmeë te aanvaar. Genoegsame gronde vir die erkenning van sodanige verwantskap is nie voorhande nie. Behalwe die klein postuur en die feit dat albei op die versamelaarspeil as jagters lewe, is daar soveel fisiese en kulturele verskille dat 'n noue rasseverwantskap nie sonder meer as 'n feit aanvaar kan word nie. Sedert die eerste publikasie van Seligman se boek oor die rasse van Afrika is heelwat nuwe gegewens oor die Pigmeë verkry (vgl. o.a. Julien se werk), en tog kan daar nog met hom saamgestem word dat hulle volkekundig nog vele geheime bewaar.

Die Boesmans en Pigmeë is eintlik alleen nog histories en volkekundig van belang. Vir alle praktiese doeleindes kan hulle tuisgebring word onder Hirschberg se banaming „Restvölker Afrikas". In die $20 \mathrm{e}$ eeu is hulle werklik nie meer as reste en daarby nog vinniger verdwynende reste van vroeër betreklik wydverspreide stamgroepe nie. Onder hierdie resvolke kan terselfdertyd ook ingesluit word die, wat herkoms betref, ewe geheimsinnige Bergdama van S.W.A., die Sandawe, Kindiga en Ndorobo in Oos-Afrika, die Wata, Duma en Boni in Noordoos-Afrika tesame met die jagerstamme in die gebied tussen die Niger en die Tsjadmeer. Hoewel hulle fisiese en rassiese herkoms onbekend is, is hierdie volke saamgebind deur die ooreenkomstige primitiewe lewe met die jag en planteversameling - ,Wildbeuterisch" noem Duitse skrywers dit - en die eenselwigheid van hulle bestemming: om in elke opsig te verdwyn in die nuwe Afrika.

Die Hottentotte is deur verskeie skrywers verbind aan die Boesmans deur die benaming Khoisan (vgl. o.a. Schapera: The Khoisan Peoples of South Africa). Die eerste deel van die naamsamestelling dui dan op die Hottentotte wat hulleself Khoi-Khoin, d.w.s. ware mense, sou genoem het. Suiwer antropologies gesien is daar sterk tekens van bloedverwantskap tussen die Khoi en die San. Afgesien van die verskil in liggaamslengte is die fisiese eienskappe van die Hottentotte merendeels dieselfde as dié van die Boesmans. Oor hoedanig via die verwantskap ontstaan het, kan alleen gespekuleer word. Die mees algemene teorie is dat die Hottentotte die resultaat was van 'n vermenging van Boesmans met suidwaarts trekkende Hamiete. Hierdie vermenging sou 
dan in die omgewing van die meergebied ontstaan het. Daaruit het 'n mensetipe nomadies herderskultuur, waarskynlik omdat die Mamitiese mans vir hulle Boesmansvroue geneem het.

Met die gesig na die ondergaande son, so word dit aanvaar, het die Hottentotte uit die streek van die groot mere verhuis, uiteindelik teen die Atlantiese Oseaan gestuit, toe suidwaarts geswenk en teen die tyd toe die blanke verversingspos aan die Kaap gestig sou word, het hulle nie alleen suid van die Gariep verspreid oor die hele noordwestelike deel wat vandag Kaapland genoem word gewoon nie maar die voorpunt het toe alreeds weer ooswaarts geswaai en hulle veetroppe in Outeniekwaland gewei. Derhalwe kon hulle leiers Van Riebeeck die verwyt toeslinger „dat sij (die blankes) op haer landt saten en sagen (sij) vast lustigh aenbanden om nimmermeer te vertrekken". Maar ook hierdie eens so verspreidwonende volk met die begeerde veetroppe het voor die aanslag van die Westerse lewenswyse nie veel meer as 'n ,resvolk" geword nie. Gedeeltelik is hulle geabsorbeer deur en vermengd met slaaf en Bantoe, as Griekwas gedeeltelik verwesters en ondergegaan, deels gedisintegreer tot blote indiwiduele „nie-blankes”, gedeeltelik noordwaarts verhuis tot oor die Oranje waar die Nama vandag of verspreid of in reservate in S.W.A. 'n tuiste gevind het. Laat ons dit byvoeg: ná 'n enigsins misdadige maar tog romantiese en avontuurlike lewe van stryd met al hulle bure, hetsy wit of swart.

Besien vanuit ons suidelike staanplek is die volgende en daarby die eerste vandag werklik aktueel belangrike rassegroep op die Afrikaanse kontinent, daardie groep volke wat bekend staan as Bantoesprekendes. In algemene terme kan beweer word dat die suidelike helfte van Afrika die tuiste van die Bantoe is. „Ten suide van 'n denkbeeldige lyn," so som die Tomlinsonverslag die posisie op, „wat strek vanaf die bog van die Wes-Afrikaanse kus ten suide van Nigerië, ooswaarts deur Frans-Ekwatoriaal-Afrika tot by die Albertmeer, met 'n suidwaartse swaai tot by die onderpunt van die Victoriameer en vandaar kronkelend ooswaarts deur Tanganjika tot by die monding van die Tanarivier aan die ooskus van Afrika, woon, met uitsluiting van 'n paar stamme, die hele Bantoe-bevolkingsgroep wat sowat 70,000,000 mense tel, 200 verwante tale en dialekte besig en in ' $n$ groot aantal stameenhede georganiseer is" (opsomming van die Tomlinsonverslag, I, 1, par. 1).

Ook hier het ons na alle waarskynlikheid met 'n fisiese mengproduk te doen nl. tussen die Afrika-negers en die Mamitiese intrekkers vanuit die noord-ooste. Fisies sowel as kultureel is die diepe spore van 
die twee komponente naspeurbaar. Die huidskleur, haar-en gelaatsvorm dra sterk Negereienskappe, maar feitlik deurgaans is die herderskultuurkomponent van die Hamiete behou, hoewel die Neger se landbou nie laat vaar is nie. Net soos die vermengingsproduk tussen Hamiet en Boesman, nl. die Hottentot, het die Bantoe ook om een of ander rede suidwaarts begin beweeg sodat volgens Theal, met redelike sekerheid aanvaar kon word in die $16 \mathrm{e}$ eeu die Bantoe noord van 'n lyn vanaf 'n punt ongeveer 25 myl noord van Walvisbaai deur die boloop van die Vaalrivier tot oos van die Drakensberge gewoon het en dan verderaf oos van die berge tot by die Umtamvun rivier.

Die Bantoe leen hom tot 'n verdere drieledige indeling. Die westelike groep word gevind in Frans-Ekwatoriaal-Afrika, die Kameroens, Belgies-Kongo en Angola (insluitende die Ambo van noordelike S.W.A.). Die Herero woon ook in hierdie westelike gebied maar behoort kultureel tot enkele oostelike Bantoestamme soos die veetelende Masai. Fisiek toon hulle sekere sterk ooreenkomste met die Oos-Afrikaanse Hamiete. Die oostelike Bantoe woon min of meer gekonsentreerd om die groot mere, d.w.s. vanaf Uganda, oor Kenia, Tanganjika, NoordRhodesië, Njasaland en Mosambiek noord van die Sambesie. Die Unie se Bantoes vorm deel van die suidelike of suid-oostelike groep wie se woonplek min of meer suid van die Sambesie langs die ooskus en binnelands tot aan die Kalahari strek.

Die deel van Afrika noord van die Bantoelyn vorm net so 'n raskundige bonte patroon as die volk-kundige ten suide daarvan. Eerste aandag verdien waarskynlik die Negers (die Soedanese groep van kaart No. 1 van die Tomlinsonverslag). Hierdie rassegroep is vandag vasgedruk ten noorde van die Bantoelyn hoofsaaklik in Wes-Afrika tot noord van Dakar. Die noordelike grens kan ruweg aangedui word met 'n geboë lyn vanaf die mond van die Senegalrivier weswaarts; reg noord van Lagos swaai dit suid, dan weer westelik met 'n sterk noordelike neiging in lyn met die bog van Biafra om 'n groot deel van die Soedan in te sluit en dan weer suid-weswaarts met allerlei inhamme tot min of meer aan Abessinië en Uganda.

Seligman noem Wes-Afrika, van die mond van die Senegal tot aan die oosgrens van Nigerië ,the home of the true Negro". Dit geld in bepaalde sin vir ủe huidige stand van sake. Hirschberg aanvaar die standpunt van Reche dat, op biologiese gronde, die oorspronklike heimat van die Neger nie gesoek moet word in die vogtig-warme reënwoude nie maar wel in die tropiese steppegebied. Sy bakermat moet dus 
eintlik in die Soedan gesoek word. Die meergenoemde rasseverspreidingskaart van die Tomlinsonverslag dui dan ook die negergebied aan as "Soedans". Volgens Reche pas die buitengewoon donker huid, donker oë, wollerige hare en ander liggaamlike eienskappe by die eise van die steppeklimaat.

Net soos die Bantoesprekendes vorm die Neger geen sterk rassiese, etniese en kulturele eenheid meer nie. Daar is ook geen aanvaarbare en eenvormige onderverdeling van die negergroep nie. „Wie ein unersättlicher Schwamm saugte der Neger im lauf seiner Geschicte zahlreiche fremde Rassenelemente in sich auf, und die Folge davon ist ein ungeheurer Typenreichtum" beweer Hirschberg (Neue Grosze Völkerkunde I, bls. 356). Die volgende interessante bewering is afkomstig van dieselfde skrywer: Die Neger, anders as die Europide volke, het nooit vrywillig sy bakermat verlaat nie. Hy was kind van die trope en gelukkig in die gematigde sone. Daar het hy veelal ook biologies die oorhand gehad oor die trope-vreemde volke. Waar hy wel die wyk geneem het uit die meer ope streke was dit onder die dwang en aanslag van krygslustige vyande. So het hy dan veral in die gebied van die middelste mere "rodend und brennend" die eens veel verder strekkende oerwoud ingedring onder aanslag van die Hamiete en is sp vernietigingswerk voortgesit deur die groot kuddes van die Hima. Net soos die Neger die vermoë sou besit om ander ras- en kultuurelemente te assimileer, sou hy ook beskik het oor die aanleg om, komende uit die grasveldstreke, hom aan te pas by die landbouvereistes van die woudgebiede.

In verband met die Hottentotte, die Bantoes en die Negers is reeds melding gemaak van die Hamitiese volke. Volgens Seligman ,the civilizations of Africa are the civilizations of the Hamites, its history the record of these peoples..." (bls. 96). Een haastige blik op 'n rasseverspreidingskaart van Afrika is genoeg om ' $n$ indruk te gee van die trekkersaard van hierdie volke. Hulle taal toon 'n invloed op dié van volke wat een-vyfde van Afrika bewoon - volgens Struck 47 tale en 71 dialekte. Hulle woon oor noordelike Afrika in kolle vanaf die horing van Afrika (die „kerngebied" van die Hamiete) suid van Mogadisjo, noordwaarts tot naby Suez, in 'n groot gebied van die noordwestelike Soedan, in kleiner eilande noord van die Senegal en in 'n betreklik lang kusstrook van Noordwes-Afrika tot aan die Middellandse See in $\mathbf{M a}$ rokko en Algerië. Met byrekening van die half-Hamitiese volke kan feitlik sonder oordrywing beweer word dat noordelike Afrika met uitsluiting van die negergebied en die betreklik klein Semitiese en Nilotiese 
cilande die tuiste van die Hamitiese volke s. Die gebied lê in 'n gordel om die weskus vanaf ' $n$ punt enigsins suid van Mogadisjo, om Afrika se noordkus en sluit in 'n deel van die noordweskus so ver as die mond van die Senegalrivier.

Die Hamiete word as Kaukasiërs, d.w.s. noue verwante van die Europese volke beskou. Gewoonlik word hulle in drie hoofgroepe onderverdeel. Die oostelike groep sluit in die ou en hedendaagse Egiptenare, die Galla van Abessinië, die Somali en Danakil en 'n groot deel van die Abessiniërs. Onder die noordelikes reken Seligman die Berbers van Tripolitanië, Tunisië, Algerië en Marokko, die Tuareg en Tibu van die Sahara en die Fula van Nigerië. Deur die geweldadige indringing van die oorspronklike Negergebied in Afrika het langs die weg van vermenging die Negro-hamitiese of gehamitiseerde Negers of half-Hamitiese groep ontstaan.

A rabië word gewoonlik as die oorspronklike geboorteland van die Hamiete aanvaar, terwyl sommige dit nog verder gaan soek en ander hulle herkoms in verband wil bring met die horing van Afrika. Laasgenoemde streek kan seker sonder veel teëspraak beskou word as die afspringplek van die Hamitiese volkere in Afrika, sodat die oostelike groep terselfdertyd aanvaar kan word as die oudste Hamitiese inwoners van Afrika. In dele van die noordelike groep -- Tripolitanië, Tunisië, Algerië fn Marokko - het ons ook rekening te hou met 'n relatief geringe Arabiese biologiese inslag maar op grond van hulle geloofsprestige 'n uitermate sterk kulturele invloed vanuit Arabiese kant. Dit wil natuurlik nie beweer dat daar nie ook betreklik suiwer $\Delta$ rabiese (d.w.s. Semitiese) groepe aangetref word nie.

Seligman plaas die half-Hamiete in Oos- en Oossentraal-Afrika, d.w.s. in die grootste gedeelte van Kenia, die deel van Uganda grensende aan die Soedan en in 'n deel van Tanganjika en sluit dan hieronder volke in soos die Masai, Nandi, Turkana e.a. wat deur die Tomlinsonverslag se bevolkingsverspreidingskaart in die Semitiese streek geplaas word. Daar is m.i. meer ten gunste van Seligman se indeling te sê, veral in ag nemende die byna fanatieke veetelerskultuur van genoemde volke.

Die Nilotiese volke het hulle naam onlleen asn hulle woongebied, t.w. die Nylvallei en onmiddellike omgewing. Hierdie naaktlopende herdersvolke is waarskynlik ook 'n tussentipe tussen die Hamiete en die Negers, dus gehamitiseerde Negers. Die bekendste volke onder hulle is waarskynlik die Nuba, Sjilluk, Dinka en Nuer. 
Hoewel Seligman onder die Semitiese volke van Afrika eintlik alleen die suiwer Arahiere insluit. heskou ander bronne nok die Ethiopiese gebied as ten minste gedeeltelik Senıities. Oor die begrip $\Lambda$ rabier met betrekking tot die inwoners van noordelike Afrika bestaan daar veel verwarring. Hier dui die term Arabier in die omgang eerder op 'n taalkundig en kulturele invloed as op 'n rasse-inhoud. Afgesien van die betreklik klein getalle werklike Arabiere van Frans-Noord-Afrika is die oorgrote meerderheid van hierdie sg. Arabiere niks anders as Berbers en andere wat die Arabiese taal en waarskynlik ook hulle godsdiens aangeneem het nie. "It is abvious", sê Seligm?n, „that in Africa the term Arab may be appointed to any people professing Islam, however much Negro or other forreign blood map run in their veins, so that while the term has a cultural value it is of little ethnic significance and is often frankly misleading". Hierdie sg. Semitiese of Arabiese gebied in Afrika val dus prakties eintlik saam met die gebied van die halfHamiete.

Abessinië kan beskou word as die ander Semitiese sentrum in Afrika. In die eerste plek was die Amhara - die eintlike Ethiopiërs wat waarskynlik enkele eeue v.C. reeds vanuit die Yemen-gebied in Arabië die latere Abessinië binnegekom het, die eerste Semitise veroweraars. Die Arabiese invloed was sedertdien altyd sterk in Abessinië, hocwel vanaf ongeveer 300 n.C. ook met Hellenistiese inslag rekening gehou moet word. Die Semitiese betekenis is natuurlik ook versterk deur die legende van die vestiging van die Salomonitiese dinastie en die verbinding van die koningin van Skeba as stammoeder van die latere Ethiopiese konings met hierdie gebied. Suiwer Semities is de gebied egter nie, want dit sluit na die suide veral belangrike Hamitiese groepe soos die Galla in.

Die mensebeeld ván Afrika moet aangevul word deur 'n kultuurbeeld. Om die antieke Egiptiese of die moderne blanke beskawings as voorbeeld van die inheemse beskawingspeil van Afrika voor te hou sal net so vals wees as om die Inca en die Maya te beskou as karakteriserend van die kulture van Suid- en Noord-Amerika respektiewelik. Hierdie voorbcelde is juis so treffend vanweë hulle uitsonderlike posisie gesien teen die agtergrond waarteen hulle oprys. Vyf, ses eeue gelede toe Afrika, hoofsaaklik omrede van sy belemmerende ligging op die suidelike seeweg na Indië en die Ooste, 'n plek in die Europese belangstelling verkry het, het nóg Afrika nóg Europa die besonderc be- 
skawingspeil van die $20 \mathrm{e}$ eeu geken of bereik en was selfs die glorie van Egipte reeds 'n begraafde grootheid.

Die kultuurbeeld van Afrika teen ongeveer die 16e en latere eeue moet hoofsaaklik gesoek word in die beskawingspeil van die Bantoes, Negers en Hamiete van die vasteland. Die sg. resvolke met hulle versamelaarskulture en swerwende bestaan, hulle primitiewe en relatief onsekere lewenswyse kon uit die aard van die saak geen belangrike beskawingsbydrae lewer nie. Op sosiaal-politieke gebied het hulle so eenvoudig en agterlik gebly as op die materiële en tegnologiese.

Gunstiger grondslae vir beskawingsontwikkeling is gebied deur die landbou en veeteelt as bedryfsvorme en materiële kultuurgrondslae. Met die oog hierop moet die aandag vir die doel van hierdie onderwerp hoofsaaklik op die sosiaal-politieke kultuurkomponente as uiting van die algemene ontwikkeling toegespits word.

Van die suid-oostelike Bantoe geld die algemene stelling dat hulle, met hulle gemengde bedryfsvorme waarin die veeteelt primêre en die landbou sekondêre plek inneem, geen groot „ryksbouers” was nie. Die stam was merendeels die sosiaal-politieke eenheid met die volksgedagte in staatkundige sin eerder op die agtergrond, min of meer soos by Israel voor die stigting van die koninkryk. In dié verband skyn daar tog twee rigtings onderskeibaar te wees. By die Nguni-groep neig dit tot 'n sterker gesentraliseerde eenheid en outokrasie. Dit is reeds merkbaar by die eindelike Nguni, nog sterker waarskynlik by die Swazi terwyl die Zulustaat soos deur Tsjaka geskep, bepaald die beste voorbeeld vorm. Selfs ook die Ndebele (Matabele) het, as vroeëre onderdeel van die Zuluvolk, onder Mzlikazi en Lobengula hierdie tradisie voortgesit. Die Sotho daarenteen het tot ' $n$ meer gedesentraliseerde, byna „demokratiese" stelsel geneig. Daarvan bied die Tswana nie 'n redelik goeie voorbeeld terwyl die verskil in optrede goeie voorbeeld terwyl die verskil in optrede tussen Moshesh en Tsjaka in die vereniging van los stamme tot 'n staatsvolk besonder sprekend is. Nogtans kan hierdie staatsvorming onder die suid-oostelike Bantoe seker nêrens vergelyking deurstaan met dié ryke van die sg. goddelike konings waarvan die Egiptiese in Afrika en die Inca in Peru van die suiwerste voorbeelde is nie. Daar was wel opvallende staatsorganisasie en -administrasie, duidelike wette e.d.m. maar 'n hoogstaande hofhouding, ontwikkeling van kuns en tegniek, 'n skryfkuns ens. het ontbreek. 
Werklike staatsbou en staatsontwikkeling moet in meer noordelike rigting gesoek word. Selfs ook van die noord-oos'elike Bantoe kan beweer word dat opperhoofde met invloed wat wyer as die stamgrense gestrek het uitsonderinge was. Die algemene kultuur het geen hoë ontwikkelingspeil bereik nie. Enigsins uitsonderlik is die kultuursituasie en beskawingspeil aan die ooskus waar die aloue handelsbetrekkinge met die Ooste die Negerinvloed sterk op die agtergrond gedring het en in die sg. Swaheli 'n vermengde kultuur van heelwat hoër peil as die binnelandse tot stand gebring het. Dit lom veral tot uiting in die differensiasie van beroepe, die beoefening van die handel, kleredrag, huishou, feeste, dekorasie, ens.

Enigsins anders geleë is die posisie in die woongebied van die westelike Bantoe. Voordat die Portugees Diago Cao in 1483 met die Kongo kennisgemaak het, het hier reeds 'n kultuur van besondere hoogte opgebloei. Volgens Bantoe tradisie is die grondslag van die Kongoryk gelê ongeveer vier of vyf geslagte voor die koms van die eerste blankes deur 'n sekere Lukeni uit die Kuangogebied. Uit die eerste nedersetting by die huidige San Salvador is die 15e eeuse Kongoryk gebore. Deur verowering het die ryk gedurende die toppunt van sy groei, net voor die koms van die Portugese gestrek vanaf Loango in die noorde waarskynlik tot by Benguella in die suide. Toe 'n oom van die Kongokoning in 1491 gedoop is - onder die invloed van die Portugese Roomse sending is die Portugese gesantskap deur die swart heerser, gesete op sy ivoortroon, ontvang. Die beskrywing van hierdie gebeure dui op groot weelde en van ' $n$ ontwikkelde hofhouding. Dapper se latere beskrywing (1670) laat ook nog genoeg gewaar van hierdie weelde maar trek eerder die aandag op die resultate van die ongewysigde toepassing van die Europese regsgedagtes op 'n Bantoestaat en van die invoering van die Europese feudale organisasie met al die titels en wardighede wat deur die Portugese kroon verleen is. Die hofhouding, leër en administrasie, uiterlik geskoei op Portugese lees het die inboorlinglewe tot in sy fondamente geskud. Die nuwere het wesensvreemd en 'n aanplaksel gebly; dit was die oorsaak van onderlinge intrige en stryd aan die hof terwyl die Roomse simbole van die Christendom reeds verval het tot bygeloofsvoorwerpe.

Ten noorde van die Kongoryk was die ooreenstemmende Loangostaat geleë en ten suide sou die Luba-Lundaryk ontstaan wat eers teen die $19 \mathrm{e}$ eeu sy hoogtepunt sou bereik. Die Luba-Lunda was 'een die helfte van die $16 \mathrm{e}$ eeu verantwoordelik vir 'n grootskaalse 
onrus en volksverskuiwings in die sentrale Bantoegebied. Hulle bring die Jaga in beroering en hierdie veroweraars sou met allesvernietigende mag tot aan die einde van die $17 \mathrm{e}$ eeu die gebied tussen die Kongo, Kuango, Kunene en die weskus in beroering bring en in die tweede helfte van die $16 \mathrm{e}$ eeu selfs die Kongoryk inval en die koning verdryf. Alleen met Portugese hulp kon hulle eers weer verdryf word.

Dit wil voorkom asof die landbouende Negers oor die algemeen 'n veel minder krygslustige lewe verkies het en in hulle woongebiede tevrede was met 'n enigsins losse politieke organisasie. Die werklike ryksvorming het meesal geskied deur die inslag van die Hamitiese en Arabiese volke en hulle kulture op die Neger. Waar die pastorale $\mathrm{Ha}$ miete geneig was tot 'n ongevestigde nomadiese krygerslewe, kon hulle eintlik op sigself geen groot ryke stig en beskawings ontwikkel wat ten minste tog 'n mate van gevestigdheid vereis nie. Waarskynlik was ook die grondslag van leeftydsgroepe wat volgens 'n vaste orde van tyd tot tyd die politieke bestuursmagte moes oorneem (bv. die Masai, Galla, Nyakyusa e.a.) minder bevorderlik in 'n hoë kultuurpeil en politieke organisasie.

Enigsins anders was die toestand wanneer die pastorale krygersvolke, hetsy Hamities of Semities, met die meer gevestigde pikbouende Negerelemente vermengd geraak het. Dit blyk gedeeltelik uit die lotgevalle van die Bantoe maar eweseer of nog sterker daar waar die Hamitiese herders ' $n$ heerserslaag oor die Negerlandbouers gevorm en daardeur self meer gevestigd geraak het en hierdie kulture van Noord-Sentraal-Afrika kry ons dan veral die posisie dat die beesteelt (in die meer woestynagtige dele die kameel) en die heersersposisie die prerogatief van die Hamitiese bolaag en die handewerk, veral die pikbou, die smedery en ander handvaardighede die verantwoordelikheid van die onderworpe Neger.

'n Sterk beskawende en staatsvormende element was terselfdertyd ook die Arabierse inslag en besonder die Mohammedanisme. Die invloed hiervan word gevolglik ook hoofsaaklik gevind in noordelike Afrika waar die Moslemkalifate 'n groot en belangrike rol gespeel het. Tog was dit nie net die Mohammedanisme wat hier 'n rol gespeel het nie. Die huidige Ghana kan ten minste terugkyk op die mite van die vroeëre Ghanaryk maar in elk geval ook op die voorbeeld van die bekende Ashanti-staat. Hierdie volk wat tot die Akangroep behoort het eers in 1900 die langdurige en bloedige stryd teen die Engelse verloor en 1720 was die Ashanti nog skatpligtig aan die Denkira maar in die- 
selfde jaar nog het hulle aangevuur deur die pasgeskepte mite van die heilige goue stoel en onder leierskap van koning Osai Tutu en priester Komfo Anotsji nie alleen hulle vryheid herwin nie, maar hulle staat oor die hele Goudkusgebied herstel. Daarop het die goue stoel tot 'n nasionaal-religieuse kultus ontwikkel.

Ook in Ethiopië is die staatsvorming en kulturele ontwikkeling histories teweeggebring deur Semitiese inslag. Reeds vanaf etlike eeue v.C. moes die veroweraars vanuit Suidwes-Arabië in verskeie golwe die gebied binnegekom en die Kussitiese volke (d.w.s. Hamiete) onderwerp het. Hulle kon wel hulle taal en kultuur op die inwoners afdwing maar het biologies self geassimileer geraak orn die Amhara te vorm. Die verdere Semitiese invloede, werklik en legendaries, die Hellinistiese kontakte en die Koptiese godsdiens is alles faktore wat verantwoordelik gehou moet word vir die groei en opkoms van hierdie besondere staat in Afrika. In die origens ,donker" Afrika vind ons hier 'n land met ' goed ontwikkelde staatsadministrasie, 'n skryftaal, 'n landboustelsel waarin terrasaanleg en die ploeg uiters belangrik is, gespesialiseerde beroepe en ampte, 'n gedifferensieerde bedryfslewe en 'n gevestigde, genasionaliseerde vorm van Christelike godsdiens.

Vermelding dien ten slotte ook nog op die buurgebied van $\Lambda$ bessinië, nl. Uganda. Reeds voor die Hamitiese oorstroming van hierdie gebiede het Uganda en die streek tussen die mere redelik goed georganiseerde state gevorm wat in menigerlei opsig met die van Darfoer en Kordofan vergelyk kan word. Moontlik was vlugtelinge uit die ryke van Napata en Meroe juis die grondleggers van hierdie state. Dan volg die verowering deur die Hamitiese Hima of Tussi wat voortaan 'n sosiaal-politieke bolaag oor die verowerde bevolkingsmassa van pikbouNegers sou vorm. Die land, volk en vee behoort an die heerser (Kabaka) wat die grond verdeel onder sy familie- en sippelede. Anders as by die Bantoe waar die stam die grond besit en die stamhoof as voog optree, vind ons hier 'n uitgeknipte feudale leenheerskap. Die hegtheid van hierdie politieke organisasie blyk o.a. daaruit dat in die gebied tans nog enkele van die state bestaan (wel onder blanke proteksie) en dat die Britse administrasie kans gesien het om met die Ugandaryls 'n verdrag te sluit en die inheemse politieke organisasic bpna onveranderd aan te wend vir sy inboorlingadministrasic.

Met hierdie Afrika sou die blanke vanaf die $16 \mathrm{e}$ eeu in toenemende mate kontak maak. Van hierdie mensegroepe sou hy geleidelik teen wil en dank maar ook grootliks deur sy eie toedoen, die voog word. 
Hierdie kulture en politieke stelsels moes hy leer ken om in sy beheer van die volke te kan besluit in hoeverre dit nuttig aangewend kan word. Die geskiedenis sou leer dat die Europeër veelal met onkundige hand ingegryp en baie van die tradisionele onherroepelik vernietig het. Hy sou deur sy dikwels hooghartige optrede die volkere in die harnas ja teen hom, hulle agterdog gaande mak en hulle vyandskap inoes. Maar deur verstand en ervaring geleer, het die blanke ook in velerlei gevalle tot die ontdekking gekom van die waarde en betekenis van die tradisionele politieke organisasie en instellinge as aansluitingspunte om die Afrikanervolke politiek en andersins te lei tot werklike en volkome vryheid.

P.U. vir C.H.O.

J. H. COETZEE.

\section{BIBLIOGRAFIE :}

Bernatzik, Hugo, A: Die Neue Grosse Volkerkunde. Bd. I (Herkul Verlaganstalt, Frankfurt A.M. 1954),

Bruwer, J. P.: Die Asiaat in Afrika in Die Asiaat en Afrika. (Sabra, Stellenbosch. 1956).

Colc, Sonia: The Prehistory of East Africa. (Penguin Books. 1954).

Flatz, Josef: Die Kulturen Ostafrikas. (Linz, 1930).

Fortes, M. M. en Evans-Pritchard, E. E.: African Political Systems. (O.U.P. 1950).

Frazer, Sir James George: The Native Races of Africa and Madagascar. (Humphries, London, 1938)

Julien, Paul: Pygmeeën. (Scheltens en Giitay, Amsterdam. s. j. Derde druk) Kommissie vir die Sosio-ekonomiese ontwikkeling van die Bantoegebiede binne die Unie van S.A. Samevatting van die verslag van. (Staatsdrukkery 1955).

Potgieter, E. F.: The Disappearing Buscmen of Lake Chrissie. (Van Schaik, Pretoria 1955)

Schapera, I.: The Bantu-speaking Tribes of S.A. (Miller, Cape Town. 1953) Schapera, I.: The Khoisan Peoples of S.A. (Routledge, London, 1930).

Seligman, C. G.: Races of Africu. (Butterworth, London. 1930).

Stow, George W.: The Native Races of S.A. (London. 1910). 